\title{
HUMANISME DALAM PERATURAN PERUNDANG-UNDANGAN KORUPSI DI INDONESIA
}

\author{
Rina Khairani Pancaningrum \\ Fakultas Hukum Universitas Mataram \\ Email : rinahukum@gmail.com
}

\begin{abstract}
ABSTRAK
Salah satu jenis kejahatan yang semakin sulit dijangkau oleh aturan hukum pidana ialah kejahatan korupsi. Bermula dari Peraturan penguasa perang pusat kepala Staf angkatan darat tanggal 16 April 1958 No. Prt/Peperpu/013/1958 beserta peraturan pelaksanaannya dan peraturan penguasa perang pusat kepala staf angkatan laut No. Prt/Z.I/I/7 tanggal 17 April 1958 hingga yang sekarang tindak pidana korupsi diatur dalam Undang-undang No. 20 Tahun 2001 tentang Perubahan atas Undang-undang No. 31 Tahun 1999 tentang Pemberantasan Tindak Pidana Korupsi. Perubahan ini terjadi untuk menjerat pelaku korupsi kelas kakap yang disebabkan oleh motif ekonomi atau karena rakus (Huruf b bagian Menimbang UU No. 20 Tahun 2001). Tidak mengherankan jika dewasa ini muncul istilah banalisme yang menyiratkan titik terendah moralitas pelaku koruptor. Kalau seseorang melakukan korupsi karena hendak memenuhi kebutuhan bertahan hidup (corruption by need), ia masih dimaklumi untuk itu, akan tetapi jika seseorang kaya dan memiliki jabatan penting di pemerintahan melakukan korupsi dan kebetulan terungkap, maka yang bersangkutan apes atau kurang beruntung. Hal demikian menunjukkan bahwa moralitas orang tersebut berada pada titik terendah, karena yang dipentingkan hanyalah aspek ekonomi semata.
\end{abstract}

Kata Kunci : Korupsi, Humanisme, Moralitas.

\section{ABSTRACT}

One type of crime that is increasingly difficult to reach by the rules of criminal law are crimes of corruption. Starting from The Center Of The Regulation Warlords Army Chief Staff dated 16 April 1958 No. Prt/Peperpu/013/1958 and its implementing regulations and Regulatory Authorities The Central War Chief Of Staff Of The Navy No. Prt/ZI/I/7 dated 17 April 1958 to the present corruption regulated in Law No. 20 of 2001 on the Amendment of Law No. 31 of 1999 on Corruption Eradication. These changes occur to ensnare high-profile corruption caused by economic motives or because of greedy (letter b section Considering Law No. 20 of 2001). Not surprisingly, today the term implies banalisme the lowest point perpetrators of corrupt morality. If someone does corruption for trying to meet the needs of survival (corruption by need), it is still understandable for it, but if someone is rich and has important positions in the government of corruption and incidentally revealed, it is concerned apes or less fortunate. It thus shows that the morality of the people is at its lowest point, because the emphasis is just purely economic aspects.

Key words : Corruption, Humanisme, Morality. 


\section{Pendahuluan}

Ketika bangsa lain sibuk berkompetisi dan menjalin kemitraan dalam percaturan dunia di bidang sains dan ekonomi, justru di Indonesia sibuk saling menjegal dan memfitnah lawan politik untuk memenangkan pemilu dengan cara tidak elegan. Tragisnya lagi, "saat jabatan telah diraih, agenda pertama adalah memperkaya diri dan setor ke partainya meski dengan jalan korupsi" (Komaruddin Hidayat, http://www.metrotvnews.com).

"Korupsi kerap membuat elektabilitas partai politik terjun bebas".(Nikky Sirait, http://jaringnews.com) Tampak dari "rilis yang dikeluarkan Sekretaris Kabinet Dipo Alam" (http://www.voaislam.com) "semakin banyak kader partai politik ditangkapi KPK, semakin anjlok elektabilitas partai politik tersebut" (Nikky Sirait, http://jaringnews.com). "Pertarungan ini akan semakin keras menjelang pemilu 2014".(http://www.voaislam.com)

Tidak saja menjelang pemilu 2014, namun sering kasus korupsi melibatkan para calon bupati, calon gubernur dan politisi lainnya menjadi spekterum pesanan politik untuk menjegal lawan dalam satu putaran pemilukada. "Bukan rahasia lagi, perkara korupsi menjadi barang dagangan" (Safari Anas, http://hukum.kompasiana.com) di lingkungan politisi hingga penegak hukum. "Suap-menyuap dan korupsi dalam dunia hukum, tampaknya bukan lagi masalah every man's need, sebagaimana dikatakan Mahatma Gandhi, melainkan masalah every man's greed karena lumpuhnya pengekangan diri, dan absennya moralitas" (Yovita A. Mangesta dan Bernard L. Tanya,
2014:12 dan Mahrus Ali, 2013:254). Benhabib berpendapat bahwa "pikiran yang kejam tidak diperlukan untuk melakukan suatu kejahatan yang brutal. Kejahatan yang brutal bisa mengambil rupa wajah orang yang baik-baik, orangorang biasa." (Reza A. A. Wattimena, 2012:111)

Situasi ini menyebabkan aparat penegak hukum tidak dapat dipercaya lagi sebagai pilar penegak hukum di tanah air. Bahkan muncul saran, "untuk menggunakan tabel interval yang menunjukkan jumlah dana yang dikorupsi dengan sanksi pidana yang dijatuhkan dalam menentukan hukuman bagi para koruptor sehingga Pengadilan Tipikor hanya bertugas membuktikan apakah betul tersangka korupsi dan berapa nilai yang dikorupsi" (Safari Anas, http://hukum.kompasiana.com).

KPK, lembaga independen yang menangani kasus korupsi mulai dikeroyok berbagai elemen di tengah kuatnya gemuruh korupsi dan koruptor menggerogoti uang rakyat, Seperti konflik lembaga antara Kepolisian dengan KPK hingga rencana DPR merevisi UU KPK. Tujuannya hanya satu: "melemahkan fungsi dan wewenang KPK" (http://www.voaislam.com), agar tidak lagi menjadi super body seperti sekarang.

Konflik ini akan semakin membuat negara mengalami disintegrasi. "Bangsa yang korup, dengki antar sesama dan ketabuan pejabat negara atau politisi untuk mengakui kesalahan serta meminta maaf kepada rakyat" (Komaruddin Hidayat, 
http://www.metrotvnews.com), disinyalir membawa "Indonesia menuju negara gagal (Failed state)" (http://www.voa-islam.com).

Kehancuran mental bangsa ini akibat terlalu lama dijajah sehingga suasana batinnya selalu ingin marah, memberontak, mencari jalan pintas, dan mereka hanya tunduk pada pemimpin yang kuat. Lamanya dijajah oleh kekuatan asing maupun pemerintahnya sendiri, menyebabkan "masyarakat tidak memiliki tradisi hidup teratur dan disiplin kecuali diancam dengan senjata" (Komaruddin Hidayat,

http://www.metrotvnews.com).

Senjata tersebut diantaranya peraturan perundang-undangan.

Manusia saat ini berindikasi cenderung modern dengan hidup sangat rasional, individual, liberal, dan materialistik. "Perangkat hati nurani mereka 'sakit' karena jarang dirawat. Mereka tidak peka dan gagal menangkap makna kehidupan. Materi yang diraih mungkin banyak tetapi simbol-simbol kekayaan belaka. Padahal kekayaan hakiki adalah kaya rohaniah." ( Sudjito, http://www.suaramerdeka.com)

Menurut Abdul Ghofur Anshori (2006:125) "manusialah yang melakukan kejahatan atas kehendak dan ikhtiarnya sendiri sehingga manusia harus mempertanggungjawabkannya".

Meskipun "darah tak akan pernah menghapus noda sejarah. Bukanlah pembantaian yang kita tangisi tetapi nurani kemanusiaan yang hilang" (Sabara Putera Borneo, http://hminews.com). Socrates pernah berkata "kenalilah dirimu, dengan dirimu sendiri" (Suhaer Fadlillah Abu
Wafiah, http://filsafat.kompasiana.com). Melihat kondisi kehidupan bangsa terutama manusia Indonesia yang makin bergeser menunjukkan adanya indikasi humanisme yang mengarah kepada humanisme sekuler. Timbul pertanyaan bagaimanakah humanisme dalam peraturan perundang-undangan korupsi di Indonesia?

\section{Metode Penelitian}

Kajian terhadap masalah ini dilakukan melalui pendekatan yuridis sosiologis yaitu untuk menjelaskan permasalahan yang dikaji secara sistematis, faktual dan akurat serta hasilnya akan dikaitkan dengan peraturan hukum yang mengaturnya dan melihat kehidupan yang senyatanya terjadi dalam masyarakat. Pendekatan yuridis sosiologis bertujuan untuk memperoleh penjelasan atas permasalahan yang dikaji beserta hasil-hasil yang diperoleh dalam hubungannya dengan aspek-aspek hukumnya, serta mencoba menjelajahi realitas empirik dalam masyarakat dalam persfektif kepentingan masa depan. Untuk memperoleh hasil yang akurat, maka penelitian ini menggunakan sumber data yang diperoleh dari data primer, data skunder dan data tertier.

a. Data primer yaitu data dan bahan-bahan hukum yang mengikat yakni Undang-undang No. 20 Tahun 2001 tentang Perubahan atas Undang-undang No. 31 Tahun 1999 tentang Pemberantasan Tindak Pidana Korupsi, Undang-undang No. 30 
Tahun 2002 tentang Komisi Pemberantasan Tindak Pidana Korupsi, Al-Quran dan yang berkaitan dengan tindak pidana korupsi.

b. Data skunder yakni data-data yang akan memberikan penjelasan mengenai data primer, seperti hasil karya dari kalangan hukum yang membahas tentang tindak pidana korupsi, data-data informasi seperti makalah-makalah seminar, artikel dalam berbagai majalah ilmiah dan sebagainya.

c. Data tertier yakni data yang akan memberikan petunjuk maupun penjelasan terhadap data primer dan data skunder, seperti ensiklopedia, kamus dan sebagainya.

Jenis-jenis dan alat pengumpulan data dalam penelitian ini yaitu studi dokumen atau bahan pustaka dan observasi atau pengamatan. Teknik analisis data yang akan digunakan dalam penelitian ini yakni menggunakan analisis secara kualitatif yakni analisis yang berusaha mendapatkan gambaran mengenai humanisme dalam peraturan perundang-undangan korupsi di Indonesia. Dengan demikian akan dicapai suatu kesimpulan dalam bentuk pernyataan-pernyataan (deskriptif kualitatif) mengenai tema yang dikaji guna mengungkap kebenaran data yang diajukan.

\section{Pembahasan}

Istilah humanisme mempunyai riwayat dan pemaknaan yang kompleks. Humanisme dikenal dalam filsafat pada awal abad ke 19. "Humanis (humanum) dimaksudkan untuk menggebrak kebekuan
gereja”.(Sabara Putera Borneo, http://hminews.com) "Gereja membuat kebebasan masyarakat Barat terkekang dalam seluruh dimensi kehidupannya, nilai-nali moral dan kemanusiaan pun direndahkan serta dilecehkan. Kebebasan berpikir dan pengembangan ilmu pengetahuan harus tunduk pada dogma Gereja, sehingga apapun yang bertentangan dengan Gereja harus ditendang." (Jauhar Ridloni Marzuq, http://www.hidayatullah.com)

Gerakan humanis berkembang dan menjadi cikal bakal lahirnya renaisance di Eropa dan "mencapai puncaknya, ketika Augusto Comte mendeklarasikan 'agama humanitarian' dan menggantikan agama yang dianggap tidak humanis" (Sabara Putera Borneo, http://hminews.com).

"Secara etimologi, renaissance berarti kelahiran kembali atau kebangkitan kembali. Mengandung arti munculnya kesadaran baru manusia terhadap dirinya (yang selama ini dikunkung oleh gereja)".(http://puntodewoblogspo tcom.blogspot.com) "Zaman ini adalah sebuah kebangkitan dengan hakekatnya bahwa manusia ditakdirkan bebas. Bebas bukan berarti liar, tetapi dalam batasbatas moral." (Dominikus Rato, 2011: 241)

"Humanisme modern dibagi menjadi dua aliran" (http://demokrasiindonesia.wordp ress.com). Pertama, humanisme keagamaan/religi yang berakar dari tradisi Renaisans-Pencerahan yang diikuti banyak seniman, umat Kristen garis tengah, dan para 
cendekiawan dalam kesenian bebas. Pandangan mereka biasanya terfokus pada martabat dan kebudiluhuran dari keberhasilan serta kemungkinan yang dihasilkan umat manusia. "Islam justru sangat mementingkan aspek kemanusian. Seluruh ajaran Islam yang diwujudkan dalam bentuk syariat Islam selalu membidik aspek kemanusiaan dan berorientasi sosial." (Jauhar Ridloni Marzuq, http://www.hidayatullah.com) Kedua, humanisme sekular mencerminkan bangkitnya globalisme, teknologi, dan jatuhnya kekuasaan agama. Humanisme sekular juga percaya pada martabat dan nilai seseorang dan kemampuan untuk memperoleh kesadaran diri melalui logika.

A. Lalande, menyatakan bahwa "humanisme adalah gerakan humanis di Eropa yang memandang manusia dalam perspektif 'manusiawi' belaka yang bertentangan dengan perspektif religius (agama) atau pandangan yang menyoroti manusia menurut aspekaspek yang lebih tinggi (seni, ilmu pengetahuan, moral, dan agama) yang bertentangan dengan aspek-aspek yang lebih rendah dari manusia. Ali Syari'ati menyebut "humanisme sebagai himpunan prinsip-prinsip dasar kemanusiaan yang berorientasi pada keselamatan dan kesempurnaan manusia" (Sabara Putera Borneo, http://hminews.com). Menurut M. Nur Ma'arif "humanistik adalah faham atau aliran yang menjunjung tinggi nilai dan martabat manusia, sehingga manusia menduduki posisi yang sangat sentral dan penting, baik dalam perenungan teoritis-filsafati maupun dalam praktis hidup sehari-hari, bukan pada kekuatan-kekuatan diluar manusia (misalnya, kekuatan Tuhan atau alam)" (http://mediaarqom. blogspot.com).

"Humanisme dari sudut pandang filsafat berakar pada pandangan mengenai manusia sebagai 'lokus semesta' yang berkesadaran, dinamis, dan dengan kemampuan akalnya senantiasa mencari makna dan nilai dalam kehidupannya" (Sabara Putera Borneo, http://hminews.com). "Humanisme menganggap rasional individu sebagai nilai paling tinggi, individu sebagai sumber nilai akhir, dan mengabdi pada pemupukan perkembangan kreatif dan perkembangan moral individu secara rasional, dan berarti tanpa acuan pada konsep-konsep yang adikodrati".(http://puntodewoblog spotcom.blogspot.com) Sikap hidup kaum humanis antara lain "kritis dan tidak mudah percaya tanpa bukti nyata (skeptis), menentang terhadap tradisi lama dan sekularisme dengan pandangan hidup carpe diem (nikmatilah hidup) yang bertolak belakang dengan pandangan hidup pada abad pertengahan yaitu momento mori (ingatlah hari sesudah mati)" (http://puntodewoblogspotcom.blo gspot.com). Inti dari humanisme adalah kebebasan. Mereka berpedoman bahwa, "kebebasan manusia itu ada, dan perlu dipertahankan dan diexpresikan" (M. Nur Ma'arif, http://mediaarqom.blogspot.com). Kenyataan yang ada "manusia lebih mementingkan nafsu dan pejabat/pemimpin kita semakin banyak yang tak peduli, sibuk urusan duniawi, entah itu korupsi 
maupun menjegal lawan politik. Di hati mereka yang ada para pengejar harta dan kuasa, Tuhan (mungkin) telah mati." (Fuza, http://coratcoretfuza. blogspot.com) Seperti pernyataan Nietzsche bahwa "Tuhan telah mati. Tuhan tidak berbuat apa-apa karena Tuhan tidak memperlihatkan kekuasaannya atau perannya ketika ada penindasan pada yang lemah oleh penguasa"

(http://sahaka.multiply.com).

"Kerakusan manusia yang telah menuhankan diri mereka sendiri menimbulkan ketidakseimbangan alam."(Jauhar Ridloni Marzuq, http://www.hidayatullah.com)

Dilihat dari segi phisikologi humanistik, berdasarkan teori hirarki kebutuhan yang diilustrasikan dalam bentuk piramida, Abraham Maslow menunjukkan hirarki kebutuhan manusia sebagai berikut: "1) kebutuhan fisiologis atau dasar, 2) kebutuhan akan rasa aman, 3) kebutuhan untuk dicintai dan disayangi, 4) kebutuhan untuk dihargai, 5) kebutuhan untuk aktualisasi diri" (http://id.wikipedia.org). Pada tingkat yang paling bawah, terdapat kebutuhan yang bersifat fisiologik (kebutuhan akan udara, makanan, minuman dan sebagainya) atau kebutuhan dasar (basic needs). Jika kebutuhan dasar tidak dipenuhi dalam keadaan yang sangat estrim (misalnya kelaparan) menyebabkan manusia yang bersangkutan kehilangan kendali atas perilakunya sendiri karena seluruh kapasitas manusia tersebut dikerahkan dan dipusatkan hanya untuk memenuhinya. Sebaliknya, jika kebutuhan dasar ini relatif sudah tercukupi, muncullah kebutuhan yang lebih tinggi yaitu kebutuhan akan rasa aman (safety needs). "Adanya kebutuhan manusia inilah dibuat peraturan perundang-undang" (http://id.wikipedia. org) untuk meredam konflik dalam pemenuhan kebutuhan.

"Tekanan utama diletakkan pada asumsi-asumsi mengenai kebutuhan-kebutuhan yang lebih tinggi. Kebutuhan-kebutuhan itu dianggap memiliki dasar sumber biologis, bagian dari hakekat manusia" (Frank G. Goble, 2012:84). "Kebutuhan-kebutuhan yang lebih tinggi (being-values) yang ditemukan Maslow yaitu sifat menyeluruh, kesempurnaan, penyelesaian, keadilan, sifat hidup, sifat kaya, kesederhanaan, keindahan, kebaikan, keunikan, sifat tanpa kesukaran, sifat penuh permainan, kebenaaran, kejujuran, kenyataan, sifat merasa cukup".(Frank G. Goble, 2012:8485) Menurut Freud, "manusia memburu kenikmatan dan menghindari rasa sakit" (Frank G. Goble, 2012:103).

Sesungguhnya untuk mencapai keselamatan dan kesempurnaan manusia yang dicita-citakan oleh humanisme yaitu "dengan membangun keseimbangan dalam hidup antara aspek teoetika atau penghambaan dengan Tuhan (ibadah), psikoetika atau penyucian jiwa dari sifat-sifat tercela, dan diwujudkan dalam bentuk pengkhidmatan kepada sesama manifestasi-manifestasinya

(manusia dan alam) atau sosioetika" (Sabara Putera Borneo, http://hminews.com). Oleh karena itu "manusia merasa perlu untuk mengetahui dirinya, dan 
sesungguhnya orang yang mengetahui dirinya maka ia mengenal Tuhannya serta memahami alam sekitarnya"(Suhaer Fadlillah Abu Wafiah, http://filsafat.kompasiana.com).

Islam memandang manusia mempunyai derajat yang tinggi, karena Islam telah memuliakannya. Tampak dari ayat-ayat Al-Qur'an yang mengukuhkan kehormatan manusia dan mengangkat kedudukannya di tempat yang paling tinggi dengan mengemban amanah dan tangung jawab besar sebagai khalifatullah di muka bumi. Kemudian Allah mengutamakan, memilih, memuliakan (dengan akal, ilmu dan intelektualitas), mendidik serta mentakdirkan manusia, sehingga kedudukannya melebihi malaikat, dan memiliki ilmu serta tangung jawab yang besarnya melebihi gunung, bumi dan langit. Manusia wajib berfikir dan berusaha memahami dirinya, alam sekitarnya, dan berusaha mengenali dirinya. Barang siapa yang mengenal dirinya sendiri, maka dia akan tahu bagaimana cara mengontrol dirinya, dan barang siapa mampu mengontrol dirinya dengan baik, maka dia akan bisa mengatur alam secara baik, sehingga dia akan menjadi khalifah-khalifah Allah. Sifat pemimpin adalah mengatur mahluk dengan menegakan keadilan, merealisasikan syari'at Allah dan mengarahkan mereka untuk memuliakan segala yang ada melalui potensi karakternya. Hal itu dilakukan sebagai realisasi kenikmatan Tuhan yang hanya diberikan kepada manusia. Ketentuan ini terdapat dalam firman Allah, Al-Qur'an Surat AlBaqarah ayat 30-34, Al-Ahzab ayat 72, dan Al-Isra' ayat 70.
Berdasarkan Hadist yang diriwayatkan oleh Muslim, Rasulullah SAW bersabda: "Barang siapa diantara kamu melihat kemungkaran, hendaklah dia merobahnya dengan tangannya. Kalau tidak sanggup (dengan tangan, maka robahlah) dengan lisannya. Dan apabila tidak sanggup (dengan lisan), maka robahlah dengan hatinya. Yang demikian itu adalah selemahlemahnya iman." (Yunahar Ilyas, Zainal Arifin Thoha dkk, 2004:3-4)

Menurut Ibn Hazm, "melalui nasehat yang diberikan secara berulang-ulang merupakan hal penting untuk memberikan penerangan bagi orang bodoh, sehingga dia mengetahui dan mau belajar etika yang baik dan perilaku yang bagus, sampai menjadi sebuah perilaku" (Suhaer Fadlillah Abu Wafiah, http://filsafat.kompasiana.com).

Tata cara memberikan nasehat menurut Ibn Hazm yaitu dengan cara "menyenangkan, senyum, lembut, seakan-akan menunjukkan sebuah ide serta memberikan pengertian yang dianggap baik oleh orang yang dinasehati. Secara rahasia atau tidak secara transparan, kecuali bagi orang yang tidak bisa memahami. Serta tanpa mensyaratkan menerima nasehatmu. Apabila engkau melanggar (melakukan) sisi-sisi ini, maka engkau adalah orang dzolim." (Suhaer Fadlillah Abu Wafiah, http://filsafat.kompasiana.com).

Dengan kata lain memberikan nasehat dengan menampilkan keteladanan Rasulullah Saw 
berdasarkan Al-Qur'an Surat Thaha ayat 44, dan Al-Imron ayat 159.

Jadi untuk mewujudkan masyarakat yang baik tidak korupsi menuntut negara untuk memberikan dorongan dan kesempatan bagi pemuasan kebutuhan-kebutuhan psikologi manusia. Jika tidak maka akan menimbulkan masyarakat yang secara phisikologis menurut Maslow sakit yaitu "tidak cukup memiliki cinta, kasih sayang, perlindungan, penghargaan, kepercayaan dan memiliki terlalu banyak permusuhan, penghinaan, ketakutan, kekejian, dan dominasi" (Frank G. Goble, 2012:173).

Terhadap penegakan hukum peraturan perundang-undangan tentang korupsi "tidak dapat sematamata dianggap sebagai proses menerapkan hukum sebagaimana pendapat kaum legalistik" (Zudan Arif Fakrulloh, http://eprints.ums.ac.id). Kesalahan utama terletak pada pereduksian objek-garapan ilmu hukum modern yang membatasi diri pada hukum positif. Padahal hukum dalam keutuhannnya merupakan sebuah tatanan (order), yang mencakup tatanan transendental (transcendental order), tatanan sosial (social order) dan tatanan politik (political order). "Hukum positif hanya menempati sudut kecil dari political order. Ilmu hukum modern secara ekstrem telah memihak pada political order, yang ditandai dengan pereduksian keutuhan realitas hukum secara luar biasa dan hanya menyisakan bagian teramat kecil yaitu hukum positif. Sikap demikian itu, identik dengan penegakan pilar regulatif-rasional, akan tetapi mengesampingkan pilar emansipatifmoral. Oleh karenanya ketaatan masyarakat terhadap hukum hanyalah sekedar ketaatan yang bersifat compliance (taat karena takut sanksi), dan bukan ketaatan yang bersifat internalization (taat karena benar-benar menganggap aturan hukum itu cocok dengan nilai intrinsik yang dianutnya)." (Sudjito, http://www.google.co.id)

\section{Simpulan}

"Mula dan akhir segala kejadian hukum adalah individu." (Supomo, 1952:2) "Individulah yang sesungguhnya menjadi akar kesatuan dari semua hukum tersebut." (J.G. Starke, 1999:99) Individu yang disangka atau telah melakukan kejadian hukum yang tergolong dalam tindak pidana korupsi. Individu yang secara biologis dikenal dengan istilah manusia dan orang dalam lingkup ilmu hukum.

"Orang-orang yang melanggar undang-undang harus dihukum. Tetapi hukuman tidak pernah boleh dipandang sebagai balasan terhadap ketidakadilan." (Theo Huijbers, 2006: 24). "Alasannya ialah bahwa pelanggaranpelanggaran merupakan suatu penyakit dalam bagian intelektual manusia (logistikon). Artinya seorang penjahat belum tau cukup tentang keutamaan yang harus dituju dalam hidup. Akan tetapi kemungkinan besar pengetahuan itu dapat ditambah melalui pendidikan, sehingga dia sembuh dari penyakitnya. Cara untuk menyembuhkan si sakit ialah melalui hukuman. Maka hukuman yang bertujuan memperbaiki sikap moral si penjahat. Tetapi seandainya penyakit itu tidak dapat 
disembuhkan, orang itu harus dibunuh." (Theo Huijbers, 2006: 25)

"Betapa pun banyaknya anggapan ketidakadilan bagi masyarakat akan kekerasan dan kekejaman hukum terhadap pelaku kejahatan, sejauh kenyataan itu tujuan umum hukuman (resmi) bukanlah untuk menyiksa atau menakuti masyarakat, melainkan bertujuan untuk mempertahankan dan meningkatkan kebahagiaan dan ketentraman masyarakat." (Abdulsyani, 1987:108) "Tujuan hukum tidaklah untuk melunasi utang-piutang atau untuk membalas dendam pada seorang penjahat, tetapi juga memastikan bahwa ia tak akan mengulangi kejahatan-kejahatannya. Hukum akan dipergunakan manakala ia merupakan satu-satunya cara untuk mencegah, penanggulangan, atau jika ia akan menakutkan orang lain untuk berbuat kejahatan. Seandainya kejahatan masa depan dapat dicegah melalui terapi yang konstruktif tanpa mengundang dilakukannya oleh yang lain, maka ia tidak efektif dan lebih memuaskan dari segi sosial daripada hukuman." (Abdulsyani, 1987:57) "Penghukuman penjahat bukan untuk mematikan atau membunuh masa depannya, tetapi justru berusaha untuk menghidupkan kembali semangat jiwanya agar dapat kembali seperti manusia warga masyarakat yang wajar." (Abdulsyani, 1987:110) Oleh karena itu peraturan perundang-undangan tentang korupsi di Indonesia harus memanusiakanmanusia dengan menjunjung hak asasi manusia yang lebih mengarah humanisme keagamaan/religi.

\section{Daftar Pustaka}

Abdul Ghofur Anshori, 2006, Filsafat Hukum Sejarah, Aliran dan
Pemaknaan, Gadjah Mada University Press, Yogyakarta.

Abdulsyani, 1987, Sosiologi Kriminalitas, Remadja Karya, Bandung.

Bambang Poernomo, 1983, Potensi

Kejahatan Korupsi Di

Indonesia, Bina Aksara.

Dominikus Rato, 2011, Filsafat Hukum Mencari, Menemukan dan Memahami Hukum, Laks Bang Justitia, Surabaya.

Fuza, Kamis, 30 Agustus 2012, Tuhan (Mungkin) Telah Mati, http://coratcoretfuza.

blogspot.com/2012/08/tuhanmungkin-telah-mati.html, Diakses pada tanggal 1 Oktober 2012.

Jauhar Ridloni Marzuq, Senin, 11 Juni 2012, Humanisme Yang Tidak Humanis, http://www.hidayatullah.com/ read/23091/11/06/2012/hum anisme--yang-tidak-

humanis!.html, Diakses pada tanggal 23 September 2012.

J.G. Starke, 1999, Pengantar Hukum Internasional, Sinar Grafika, Jakarta.

Komaruddin Hidayat, Senin, 13 Agustus 2012, Mengakhiri Mitos Bangsa yang Kalah, http://www.metrotvnews.com /metromain/analisdetail/2012 /08/13/280/MengakhiriMitos-Bangsa-yang-Kalah, Diakses pada tanggal 1 Oktober 2012.

M. Nur Ma'arif, Kamis, 03 Juli 2008, Kedudukan Menusia Dalam Filsafat Humanistik Dan IlmuIlmu Sosial Humanistik, http://mediaarqom.blogspot.co $\mathrm{m} / 2008 / 07 /$ filsafat- 
humanistik.html, Diakses pada tanggal 23 September 2012.

Mahrus Ali, 2013, Asas, Teori \& Praktek Hukum Pidana Korupsi, UII Press, Yogyakarta

Nikky Sirait, Minggu, 8 Juli 2012, Awas, Dibandingkan Demokrat, Nasib Golkar Bisa Lebih Terpuruk, http://jaringnews.com/politikperistiwa/umum/18368/awasdibandingkan-demokrat-nasibgolkar-bisa-lebih-terpuruk, Diakses pada tanggal 1 Oktober 2012.

Sabara Putera Borneo, 12 August 2010, Humanisme dalam Tinjauan Sains, Filsafat, Spiritualisme, http://hminews.com/news/human isme-dalam-tinjauan-sains-filsafatspiritualisme/, Diakses pada tanggal 23 September 2012.

Safari Anas, 02 September 2012, Situasi Begini; Hukuman Koruptor Harus Pakai Tabel, http://hukum.kompasiana.com/20 12/09/02/situasi-begini-hukumankoruptor-harus-pakai-tabel/, Diakses pada tanggal 1 Oktober 2012.

Sudjito, 28 Maret 2007, Perkembangan Ilmu Hukum: Dari Positivistik Menuju Holistik Dan Implikasinya Terhadap Hukum Agraria Nasional Yogyakarta, http://www.google.co.id/url?sa=t\& rct=j\&q=prof $\% 20 \mathrm{dr} \% 20$ sudjito $\% 2$ C\%20sh\%2C\%20msi\%20guru\%20 besar\%20dan $\% 20$ ketua $\% 20$ progra m\%20doktor\%20ilmu\%20hukum $\% 20$ ugm $\% 20 \&$ source=web\&cd=1\& cad $=$ rja\&ved $=0$ CCAQFjAA\&url=http $\% 3 \mathrm{~A} \% 2 \mathrm{~F} \% 2 \mathrm{Fmgb} . u g m . a c . i d \% 2 \mathrm{Fm}$ edia $\% 2$ Fdownload $\% 2 F$ pidatopengukuhan.html\%3Fdownload \%3D64\&ei=WxFpULyxA8_PrQft6ID QCw\&usg=AFQjCNEqyswgOzsXRM
aqHQ9xfAYGv_9ciw, Diakses pada tanggal 1 Oktober 2012. -----, 08 September 2012, Teladan Bernegara Hukum, http://www.suaramerdeka.co $\mathrm{m} / \mathrm{v} 1 /$ index.php/read/cetak/2012/0 9/08/198081/TeladanBernegara-Hukum, Diakses pada tanggal 1 Oktober 2012.

Suhaer Fadlillah Abu Wafiah, 03 August 2011, Filsafat Humanisme Islam (Terjemah Buku Al-Falsafah Al-Insaniah Fil Islam), http://filsafat.kompasiana.com /2011/08/03/filsafathumanisme-islam-terjemahbuku-al-falsafah-al-insaniah-filislam/, Diakses pada tanggal 23 September 2012.

Supomo, 1952, Hubungan Individu Dan Masyarakat Dalam Hukum Adat, Jajasan Dharma, Djakarta.

Theo Huijbers, 2006, Filsafat Hukum Dalam Lintasan Sejarah, Kanisius, Yogyakarta.

Yunahar Ilyas, Zainal Arifin Thoha dkk, 2004, Korupsi Dalam Perspektif Agama-Agama (Panduan Untuk Pemuka Uamat), Kutub, Yogyakarta.

Yovita A. Mangesta dan Bernard L. Tanya, 2014, Moralitas Hukum, Genta, Yogyakarta.

Zudan Arif Fakrulloh, Penegakan Hukum Sebagai Peluang Menciptakan Keadilan, Jurisprudence, Vol. 2, No. 1, Maret , Halaman 22, http://eprints.ums.ac.id/346/1 /2._ ZUDAN.pdf, Diakses pada tanggal 1 Oktober 2012.

Reza A. A. Wattimena, 2012, Filsafat Anti-Korupsi Membedah Hasrat 
Kuasa, Pembaharuan Kenikmatan, Dan Sisi Hewani Manusia Di Balik Korupsi, Kanisius, Yogyakarta Abraham Maslow, http://id.wikipedia.org/wiki/Abra ham_Maslow, Diakses pada tanggal 1 Oktober 2012.

Sejarah Intelektual Barat Zaman Renaissance Dan Humanisme, http://puntodewoblogspotcom.blo gspot.com/2012/05/sejarahintelektual-baratzaman. html, Diakses pada tanggal 23 September 2012.

Filsafat

Humanisme,

http://sahaka.multiply.com/journa l/item/20/Filsafat-Humanisme?\& show_interstitial $=1 \& u=\% 2$ Fjournal \%2Fitem, Diakses pada tanggal 23 September 2012.

38 Tokoh Humanisme Dunia Paling Berpengaruh Sepanjang Sejarah Kehidupan Manusia, http://demokrasiindonesia.wordpr ess.com/2012/07/20/38-tokohhumanisme-dunia-palingberpengaruh-sepanjang-sejarah- kehidupan-manusia/, Diakses pada tanggal 23 September 2012.

Genderang Perang Antara Partai Politik Ditabuh,

http://www.voa-

islam.com/news/opini/

2012/09/29/20920/genderan g-perang-antara-partai-politikditabuh/, Diakses pada tanggal 1 Oktober 2012.

Layak DPR Menjadi Musuh Seluruh Rakyat?, http://www.voaislam.com/news/opini/2012/ 09/27/20889/layak-dprmenjadi-musuh-seluruhrakyat/, Diakses pada tanggal 1 Oktober 2012.

Undang-undang No. 20 Tahun 2001 tentang Perubahan atas Undang-undang No. 31 Tahun 1999 tentang Pemberantasan Tindak Pidana Korupsi.

Undang-undang No. 30 Tahun 2002 tentang Komisi Pemberantasan Tindak Pidana Korupsi

Al-Quran dan terjemahannya 